\title{
The viability of domestic rainwater harvesting in the residential areas of the Liesbeek River Catchment, Cape Town
}

\author{
LN Fisher-Jeffes ${ }^{1 *}$, NP Armitage' and K Carden' \\ 'Department of Civil Engineering, University of Cape Town, Private Bag X3, Rondebosch 7701, South Africa
}

\begin{abstract}
By 2030 South Africa (SA), a developing country, is predicted to be severely impacted by physical water scarcity. In order to avert a future water crisis, the country needs to find ways to reduce its reliance on conventional surface water schemes based on impoundments on rivers. Rainwater harvesting $(\mathrm{RWH})$ is an alternative water resource. To date, the viability of domestic RWH within an urban setting has not been adequately considered in SA. The purpose of this study was thus to address this omission through the detailed modelling of a representative catchment. The Liesbeek River Catchment in Cape Town comprising some 6200 domestic properties in 6 suburbs covering an area of around $1300 \mathrm{ha}$ - was chosen for this purpose; and a new computational tool, the Urban Rainwater/Stormwater Harvesting model (URSHM), was developed to take best advantage of the available data. The analysis showed that: RWH was only economically viable for a minority of property owners; climate change is likely to have limited impact on the performance of RWH systems; and - contrary to some claims - RWH is an unreliable means of attenuating peak stormwater flows.
\end{abstract}

Keywords: domestic rainwater harvesting, alternative water resources, developing country

\section{INTRODUCTION}

South Africa (SA) is a water-stressed, developing country facing a range of challenges with respect to water management, inter alia, resource shortages, environmental degradation, fragmented institutional structures and basic services backlogs (Kok and Collinson, 2006; DEA, 2010; Fisher-Jeffes et al., 2012; DWA, 2013). The existing situation with respect to water scarcity in SA is aggravated by the fact that freshwater resources are unevenly distributed and disproportionally available relative to demand (UNDP et al., 2000; Blignaut and Heerden, 2009; Carden, 2013)\{FormattingCitation\}. Whilst there have been extensive investigations around the country considering where and how best to implement different water resources, including new dams, raising dam walls, exploiting aquifers and desalination facilities (DWA, 2013), there exists a historically-entrenched paradigm promoting the centralised provision of water over de-centralised options such as rainwater harvesting (RWH) in urban areas.

Internationally, RWH - the collection and storage of runoff from the roof/s present on an individual property within urban areas, and the subsequent use within that property - is increasingly being seen as an underutilised water resource that may be used to increase the resilience of urban water supply systems. On the other hand, international experience also suggests that RWH is a relatively expensive alternative water resource (e.g. Marsden Jacobs Associates, 2006) - which may make it inappropriate for poorer communities. By way of contrast, the promotion of RWH in SA has been largely targeted at rural, largely poor communities; e.g. Mwenge Kahinda et al. (2010), who investigated the viability of RWH in different parts of SA but used methods that have been shown in other studies (e.g. Neumann et al., 2011) to potentially lead to considerable errors in the estimates of yield. Research looking at the potential for RWH in urban residential areas has mainly seen it as a means of supplementing outdoor demand only (e.g. Jacobs et al., 2011).

\footnotetext{
* To whom all correspondence should be addressed.

e-mail: 1loyd.fisherjeffes@gmail.com

Received: 8 June 2016; accepted in revised form: 6 December 2016
}

For RWH to be a viable resource in SA urban residential areas, it is necessary to: understand the potential financial and economic implications (for both the residents and the local authority); estimate the potential reliability of supply of RWH in SA; identify and mitigate the potential risks; and ensure that where RWH schemes are implemented they are designed sustainably (socially, economically and environmentally). This study aimed to contribute to this through the detailed modelling of the potential adoption of RWH on the residential properties situated in the Liesbeek River Catchment, located in the southern suburbs of Cape Town, SA.

\section{Modelling multiple RWH systems: Key literature findings}

Modelling rainwater harvesting (RWH) at a system scale is relatively simple and there are an abundance of available models. When modelling the cumulative performance of a number of RWH systems - for example, within a catchment - a common approach has been to linearly extrapolate the quantity and quality performance from a single 'typical' RWH system. This includes: total water demand met, volumetric reliability, total runoff, per cent of harvested runoff, and the cost per kilolitre (Neumann et al., 2011; Maheepala et al., 2013). Such an approach, however, assumes that, inter alia: every RWH system supplies much the same amount of water at much the same time; every RWH system has roughly the same size catchment area (roof area); and rainfall and evaporation are relatively constant in both time and space, etc. (Maheepala et al., 2013). While this is clearly never the case, many studies have made such broad assumptions - likely due to the simplicity of such an approach - as illustrated by DeBusk and Hunt (2014) who identified several studies that evaluated the performance of multiple RWH systems, all of which made use of averaged data and/or upscaling. Ghisi et al. (2007), for example, made use of average roof areas, average household size and average percapita demand for 195 cities in Brazil. They concluded that the performance of a RWH system based on a specific city's data was equivalent to what that city might expect from multiple 
RWH systems. However, other authors (Mitchell et al., 2008; Xu et al., 2010; Coultas et al., 2011; Maheepala et al., 2011; Mashford et al., 2011; Newmann et al., 2011; and Maheepala et al., 2013) have all shown that the use of linear extrapolation of the performance of RWH at an individual property scale to the regional scale can lead to significant errors in the estimates of yield (up to 24\%), overflow (up to 37\%) and water quality. Linear upscaling of the performance of RWH for an average system should thus be avoided. As an alternative, some researchers have suggested that analyses should rather consider a stochastic approach - where the input parameters for each RWH system are randomly assigned based on probability in order to better represent the likely performance of RWH systems (Mitchell et al., 2008; Coultas et al., 2011; Mashford et al., 2011; Neumann et al., 2011; Maheepala et al., 2013). The descriptive statistics (mean, minimum, maximum, standard deviation) of roof areas, depression storage, tank size and effective roof area factors are typically extracted from values reported in literature from local studies and/or personal communication with a local water industry.

A number of stormwater management guidelines (e.g. Woods-Ballard et al., 2007) suggest that, in instances where it is has been widely adopted, RWH may provide stormwater management benefits, particularly peak flow attenuation. Researchers such as Petrucci et al. (2012), however, show that rainwater tanks 'affect the catchment hydrology for usual rain events, (but) are too small and too few to prevent sewer overflows in the case of heavy rain'. Furthermore, Mitchell et al. (2008); Coultas et al. (2011); Mashford et al. (2011); Neumann et al. (2011); and Maheepala et al. (2013) all indicate that the potential reduction of spillage from RWH tanks is often significantly overstated. All in all, the potential attenuation of peak flows is likely to be insignificant during the type of major rainfall event for which it would have been most useful. There may well, however, be significant water quality benefits as these are usually associated with the smaller, more frequent, events.

\section{Liesbeek River Catchment case study}

In order to assess the potential of domestic RWH in SA, it was decided to select and model a representative catchment. As a result of data constraints, especially data availability, the method needed to be customised to the selected catchment.

A number of catchments in Cape Town were considered, including, inter alia: the Salt River (the catchment was considered to be too large and complex), Disa River (the catchment was considered to be too small with insufficient development diversity and poor data availability), and the Sand River (too many informal settlements - deemed to be inappropriate for this assessment which was focused on formal housing - and poor data availability). The Liesbeek River Catchment (Fig. 1), situated on the slopes of Table Mountain, was ultimately selected as it incorporates a diversity of land uses, represents a range of wealth levels, has significant historical importance for the City of Cape Town (CoCT) and SA, and had the necessary data available for the effective development of the detailed models required for simulating catchment-wide RWH. The catchment covers approximately 2600 ha. The Liesbeek River itself is approximately $9 \mathrm{~km}$ long and is fed by numerous streams running down the eastern slopes of Table Mountain. Precipitation and evaporation vary substantially across the catchment. The maximum annual rainfall (1500 mm/yr.) is 2.5 times the minimum ( $600 \mathrm{~mm} / \mathrm{yr}$.). While less significant, evaporation also varies - between $1300 \mathrm{~mm} / \mathrm{yr}$ and $1550 \mathrm{~mm} / \mathrm{yr}$
- across the catchment. Rainfall and evaporation has a significant impact on the viability of RWH. Urbanisation has had a large impact on the river - especially in the lower reaches. Six of the officially recognized suburbs of the CoCT are either partially or entirely located within the catchment (CoCT, 2009).

The available UWM models generally take one of the following three approaches: (i) assume linear upscaling (e.g. UVQ (Mitchell and Diaper, 2005)); (ii) require the modelling of every property individually in an unnecessarily time-consuming manner that requires considerable computing power (e.g. SWMM (USEPA, 2004)); or else (iii) make use of statistical distributions for the different modelling parameters (e.g. Mitchell et al., 2008).

None of the above-mentioned approaches seemed appropriate for RSA. There is a dearth of suitable data for RWH in urban residential areas. Additionally, the local socioeconomic situation is likely very different from those countries where most of the research has been carried out to date. Thus, in order to best test the viability of RWH for water supply and flood peak mitigation in a SA urban residential catchment, a new model called the 'urban rainwater/stormwater harvesting model' (URSHM) was developed (Fisher-Jeffes et al., 2014; Fisher-Jeffes, 2015). The model, inter alia:

- Allows for different end uses and treatment options to be considered

- Identifies the optimum design from a number of different scenarios

- Estimates the individual and catchment scale volumetric reliability of RWH systems

- Estimates the reduction in runoff volume

- Estimates the economic costs and, where possible, the benefits of RWH

- Estimates the expected variation in each variable at different levels of adoption of RWH

The URSHM combines many well-known techniques such as life-cycle costing and behavioural analysis with a simplified water balance for typical RWH systems (Fig. 2) in a manner that can be scaled to take into account various different parameters, e.g., larger roof area or bigger pump, depending on the property's characteristics. The URSHM can, where data exists, as was the case in this study, be used to undertake an analysis of thousands of individual properties and aggregate the results to the catchment level.

The URSHM requires the following data:

- Roof area - the roof area that potentially could be connected to the storage tanks. It was evident that it would not be reasonable to assume a normal distribution for roof areas as analysis of the available data showed that the roof area distributions varied between suburbs and that - even if they could be assumed to be normally distributed within a suburb - no local data existed to suggest the appropriate statistics to use. In the case of this study, all of the roof areas were manually captured from orthophotographs. This resulted in the classification of development footprints / roof areas for approximately 6200 properties.

- Effective roof area factor - a factor equal to or less than one, that accounts for continuous losses due to splashing and gutter overflow which will reduce the volume of runoff that may be collected and stored. 
- Rainfall data - the amount of rain landing on the roof that could potentially run off. In this study, daily precipitation data was obtained from the South African Weather Service, Department of Water Affairs, and local residents.

- Evaporation data - used to calculate losses from open bodies of water. In this study, evaporation data was obtained from the South African Weather Service and Department of Water Affairs for 2 stations within the Liesbeek River Catchment and 5 stations in neighbouring catchments. The data from the 7 stations was used to interpolate measurements across the catchment.

- Depression storage - the precipitation stored in surface depressions on the roofs. In line with Mitchell et al. (2008) and Neumann et al. (2011), amongst others, it was assumed that depression storage and runoff coefficients could be assumed to be normally distributed as these are the products of an 'infinite number of independent random events' (StatSoft Inc., 2013). Each property was thus assigned a once-off value (constant for this study) and modelled with its assigned runoff coefficient and depression storage values for all analyses.

- Tank size - the maximum storage volume prior to overflow. There were no data as to what an appropriate size RWH tank would be in the catchment and how this might relate to other parameters, e.g., roof area or demand. It was therefore decided to make use of the URSHM, as will be discussed in the following section, to determine the optimum RWH system for each property in the catchment based on the standard tank sizes offered by suppliers $(0.5 \mathrm{~kL}, 1 \mathrm{~kL}, 1.5 \mathrm{~kL}$, $2.2 \mathrm{~kL}, 5 \mathrm{~kL}, 10 \mathrm{~kL}, 15 \mathrm{~kL}, 20 \mathrm{~kL}, 25 \mathrm{~kL}$ and $30 \mathrm{~kL}$ ).

- Demand data - water used by the target constituency for various purposes. In order to estimate indoor water demand an assumption was made that water demand during winter, when there is generally abundant rainfall (Cape Town is a winter rainfall area), would equate to the indoor demand alone. This approach has been used elsewhere (e.g. Howe and Linaweaver, 1967) and is supported by end-use modelling which suggests that outdoor irrigation in Cape Town is almost exclusively limited to the summer months. This approach is more fully detailed in Fisher-Jeffes et al. (2014) and Fisher-Jeffes (2015). The indoor demand split by enduse was then estimated using indicative figures given in the literature (e.g. Mayer et al., 1999; Jacobs and Haarhoff, 2004; Roberts, 2005; Willis et al., 2009; Beal and Stewart, 2011;) and superimposed on a diurnal water demand pattern presented by Mayer et al. (1999).

\section{Sizing of RWH systems}

The URSHM assumes that individuals act rationally and choose the optimum system according to one of four objective functions shown in Table 1. These objective functions look at various ways end-users might make use of a RWH. The optimum system is then automatically selected for each property and summed to the catchment scale. The output includes: total water demand met, volumetric reliability, total runoff, per cent of runoff notionally harvested, and average cost per kilolitre.

In general, the largest available tank size will provide the greatest volumetric reliability as it will store the greatest volume of water. The optimisation process was thus designed to minimise the lifecycle cost per kilolitre at the household level.

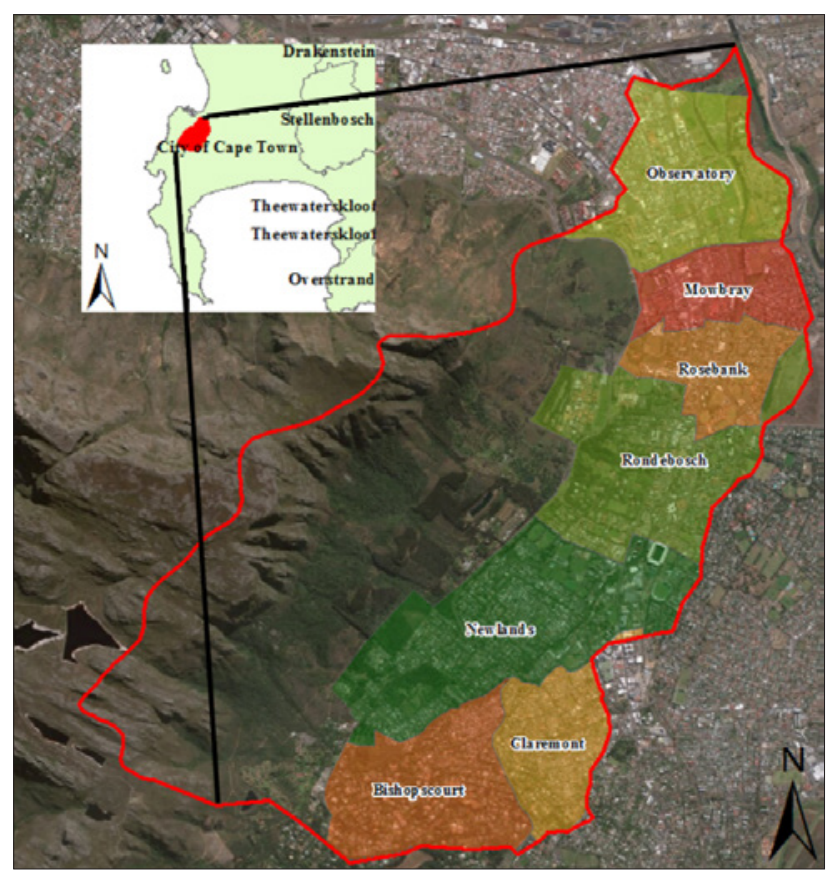

Figure 1

Liesbeek River catchment

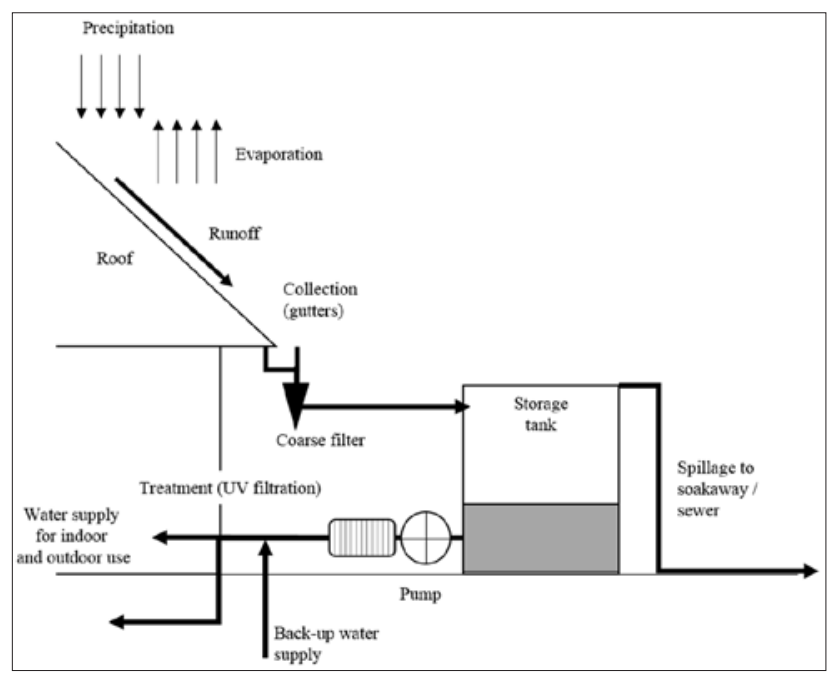

Figure 2

Typical RWH system modelled by the URSHM

\section{Scenario analysis}

A total of 20 scenarios - essentially combinations of contributing roof area and end-uses (Table 2) - were analysed for the Liesbeek River Catchment using the available 10 years of rainfall data in order to assess the likely viability of RWH. Scenarios 1-10 assumed that the whole roof of each property potentially contributes to RWH. Scenarios 11-20 were identical to Scenarios 1-10 except that this time it was assumed that the connected roof area was $100 \mathrm{~m}^{2}$ or $50 \%$ of the roof area, whichever was the lesser in line with the MP 4.2 planning requirements of Queensland, Australia (DLGP, 2008). The scenarios (1-10;11-20) represented various combinations of what may be considered appropriate 'fit for purpose' uses of harvested rainwater in the CoCT based on the literature (e.g. Burns et al., 2012). Scenarios 1, 2, 11 and 12 assumed gravity feeds without disinfection. The other scenarios included pumps as well as UV disinfection. 


\begin{tabular}{|l|l|l|}
\hline \multicolumn{2}{|c|}{ System optimisation objective functions } \\
\hline Objective Function & Description & $\begin{array}{l}\text { Rational motivation for selecting system using } \\
\text { objective function }\end{array}$ \\
\hline Objective Function A & $\begin{array}{l}\text { System optimised to minimise the cost per kL of harvested } \\
\text { rainwater. }\end{array}$ & $\begin{array}{l}\text { Minimal negative financial impact on the end user if a } \\
\text { municipality forces the adoption of RWH. }\end{array}$ \\
\hline Objective Function B & System optimised to maximise volumetric reliability. & $\begin{array}{l}\text { Provides maximum water supply security. May be } \\
\text { appropriate in areas where water supply is intermittent. }\end{array}$ \\
\hline Objective Function C & $\begin{array}{l}\text { System optimised to maximise volumetric reliability while } \\
\text { ensuring the cost per kL of harvested rainwater is less than } \\
\text { the average cost per kL of potable water from the CoCT. }\end{array}$ & $\begin{array}{l}\text { Where the adoption of RWH is left to the end user/s, who } \\
\text { is/are motivated primarily through the potential to make } \\
\text { financial savings. This objective function may result in a } \\
\text { substantial number of individuals not adopting RWH if the } \\
\text { price of water is too low. }\end{array}$ \\
\hline Objective Function D & $\begin{array}{l}\text { System optimised according to user selected weighting of } \\
\text { the cost per kL and the volumetric reliability. Default setting } \\
\text { assumes equal weighting. }\end{array}$ & $\begin{array}{l}\text { Where financial concerns and water security concerns need } \\
\text { to be balanced. Essentially combines objective functions } \\
\text { A and B. }\end{array}$ \\
\hline
\end{tabular}

\begin{tabular}{|c|c|c|c|}
\hline \multicolumn{4}{|c|}{$\begin{array}{c}\text { TABLE } 2 \\
\text { RWH Scenarios (11-20 represent reduced roof areas) }\end{array}$} \\
\hline $\begin{array}{l}\text { Scenario }(100 \% \\
\text { roof area) }\end{array}$ & $\begin{array}{l}\text { Scenario }\left(100 \mathrm{~m}^{2} \text { or }\right. \\
50 \% \text { roof area })\end{array}$ & End-use water demand description & RWH system description \\
\hline Scenario 1 & Scenario 11 & Supplying pools only & Gravity fed, no UV treatment \\
\hline Scenario 2 & Scenario 12 & Supplying garden irrigation only & Gravity fed, no UV treatment \\
\hline Scenario 3 & Scenario 13 & Supplying washing machine only & Directly pumped \\
\hline Scenario 4 & Scenario 14 & Supplying toilet flushing only & Directly pumped \\
\hline Scenario 5 & Scenario 15 & Supplying showers / bath only & Directly pumped \\
\hline Scenario 6 & Scenario 16 & Supplying toilet flushing, washing machine only & Directly pumped \\
\hline Scenario 7 & Scenario 17 & Supplying washing machine, shower/bath only & Directly pumped \\
\hline Scenario 8 & Scenario 18 & Supplying toilet flushing, washing machine, shower/bath only & Directly pumped \\
\hline Scenario 9 & Scenario 19 & Supplying toilet flushing, washing machine, shower / bath, pool only & Directly pumped \\
\hline Scenario 10 & Scenario 20 & $\begin{array}{l}\text { Supplying toilet flushing, washing machine, shower / bath, pool, } \\
\text { garden, irrigation only }\end{array}$ & Directly pumped \\
\hline
\end{tabular}

\section{RESULTS AND DISCUSSION}

\section{Economic analysis assuming current climatic conditions}

Figure 3 presents the results of an analysis assuming 100\% adoption of RWH throughout the catchment, with RWH systems optimised using OF B using the Yield After Storage (YAS) algorithms (Roebuck, 2007) for storage and an hourly timestep. It indicates that Scenario 1, where RWH is considered for filling pools, would only reduce the annual potable water demand by a maximum of $1.3 \%$ (28 ML/yr), while Scenario 2, which considers RWH for garden irrigation, would only reduce the annual water demand by up to $9.5 \%$ (200 ML/yr). Furthermore, throughout much of the winter, the storage tanks will be quickly filled and then overflow offering little beneficial use as there is sufficient precipitation not to require the topping up of swimming pools. This is also evident in the relatively low volumetric reliability for Scenarios 1 and 2, even though the demand is significantly less than in other scenarios.

Figure 3, however, also indicates that as RWH is considered for more end uses such as toilet flushing, washing machine use, shower/bath use, as well as pool and garden irrigation (Scenarios 3-10), increasing overall demand may be met. However, this is generally at the cost of a decreasing volumetric reliability (water demand met divided by total water demand) depending on the end uses in question. For example, while Scenarios 8-10 meet roughly the same water demand, Scenario 10 has a significantly lower volumetric reliability due to the additional outdoor irrigation demand which is typically present during the dry season. As a consequence, the choice of end uses is important for the system operator (generally the homeowner), who may wish to have a system with a higher volumetric reliability - ability to meet water demand - and rather look for an alternative source of water for irrigation. This latter could, for example, include greywater or groundwater.

Results for Scenario 10 (maximum demand) indicate that a reduction of up to $47 \%$ of runoff volume is possible. However, Figure 3 does not show whether the cost of developing and operating individual RWH systems is affordable. On the other hand, there is limited difference in the performance of RWH between Scenario 8 (supplying toilet flushing, washing machines, showers/bath only), Scenario 9 (supplying toilet flushing, washing machine, shower/bath and pools) and Scenario 10 (supplying toilet flushing, washing machine, shower/bath, pools and garden irrigation). This further supports the notion that RWH for the purposes of irrigation in a winter rainfall area provides little benefit.

Figure 4 presents the same analysis as per Fig. 3 for Scenarios 11-20 (the RWH system is assumed to be connected to the lesser of $100 \mathrm{~m}^{2}$ or $50 \%$ roof area). The same trends in performance are evident; however, the demand met, volumetric reliability and reduction in spillage are significantly less. Clearly, RWH systems should be connected to as much of a property's roof area as possible in order to maximise the benefits of the system and thus all further discussion in this paper refers to Scenarios 1-10.

A significant challenge to the wider adoption of RWH in RSA (and elsewhere) is that the cost of RWH typically has an 


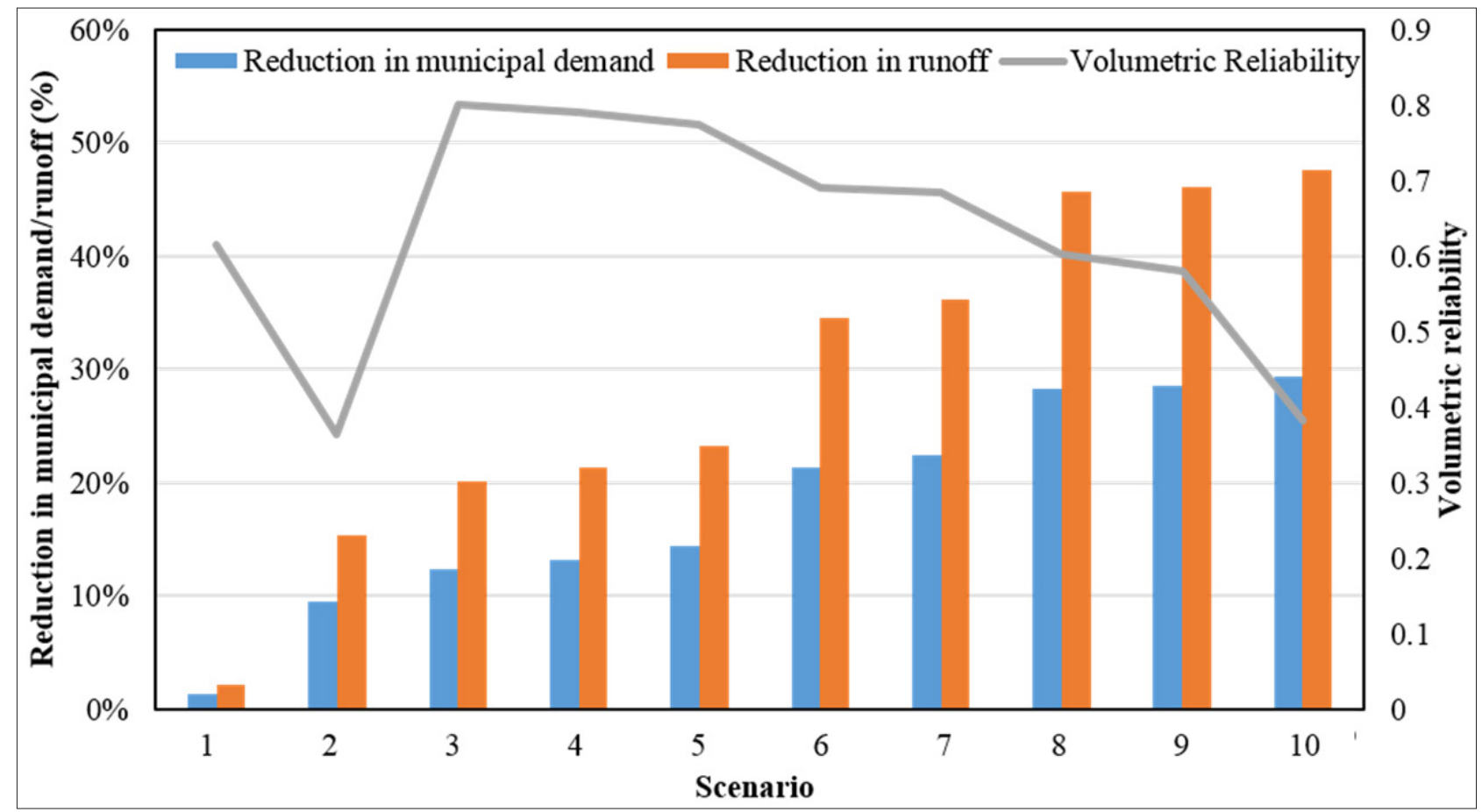

Figure 3

Potential reduction in demand through water savings as a percentage of total demand (Scenarios 1 through 10)

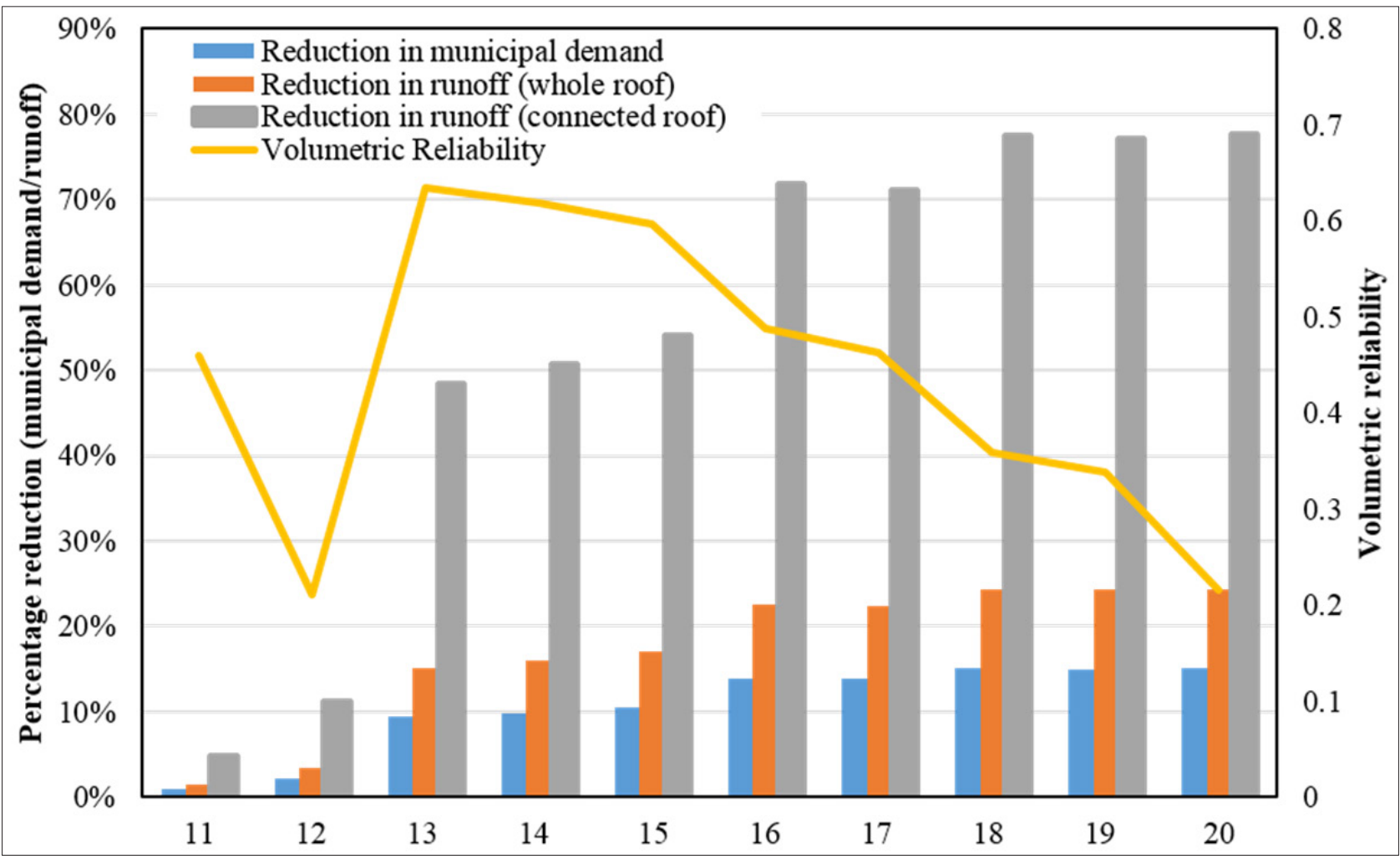

Figure 4

Potential reduction in demand through water savings as a percentage of total demand (Scenarios 11-20)

inverse relationship with water demand. As a result, the CoCT's current block tariff structure, which has no charge for the first $6 \mathrm{~kL} / \mathrm{hh} \cdot \mathrm{mnth}$ and then increasing unit rates as the monthly demand increases, acts as a disincentive to small users of water to harvest rainwater, even if, at a per capita level, they are using large volumes of water. Consequently, at 2013 water tariffs, only
$488(8 \%)$ of the households within the catchment would likely be economically incentivised to install RWH systems assuming the adoption of Scenario 8 (supplying toilet flushing, washing machine, shower/bath only). This increases to 590 (9.5\%) households, assuming the adoption of Scenario 10 (supplying toilet flushing, washing machine, shower/bath, pools and garden 
irrigation). Essentially, as a result of the relatively cheap cost of municipal water at the moment, RWH is not financially viable for the majority of households.

Assuming the saving realised through installing and operating RWH systems is a significant driver for their adoption, Fig. 5 shows the maximum annual potable water savings (ML/yr) that may be realised in the Liesbeek River Catchment depending on the rational selection of RWH by property owners based on the cost of municipal water in the catchment (this includes the sanitation charge, as the CoCT's sanitation charge is based on the volume of water supplied) and no subsidy. The cost of water in Fig. 5 is represented by a 'Tariff Multiplier', i.e., the proposed tariff divided by the actual (2013) tariff based on OF $\mathrm{C}$ (system optimised to maximise volumetric reliability while ensuring the cost per kilolitre of harvested rainwater is less than the average cost per kilolitre of potable water from the CoCT; Table 1) assuming the full roof size for collection and $100 \%$ adoption of RWH by property owners such that the cost of the RWH was equal to or less than the cost of water supplied by the municipality.

Figure 5 suggests that Scenarios 1-5 would all require significant increases in water tariffs before there is much likelihood of a significant reduction in the volume of water that needs to be supplied by the municipality as a result of the voluntary uptake of RWH by individual residents. Probably the most promising of these options is Scenario 2 which only requires a doubling of the water tariffs to achieve roughly the same savings as could be achieved by tripling the water tariffs for Scenarios 3-5. However, Scenario 2 assumes gravity irrigation without further treatment. The use of gravity irrigation (including carrying buckets of water), from a social perspective, is unlikely in more affluent areas with bigger gardens. As a consequence, should RWH be considered in the CoCT and the rest of RSA, it would be important to encourage the installation of systems in which water is used as diversely as possible (i.e. Scenarios 6-10). This would reduce the scale of the required adjustment to the tariffs in order to incentivise users to adopt RWH while concurrently ensuring a greater reduction in demand for municipal water.

Figure 6 indicates that the properties that are incentivised through the increase in tariffs are typically those that have higher water demands and are in wealthier suburbs, as would be expected. This is important, as it indicates that in SA, RWH in urban areas is more appropriate for wealthier households. The focus of any educational, marketing or incentivisation scheme should thus be targeted at them.

Overall, it would appear that RWH is most likely to be a viable option when the harvested rainwater is used for as many end uses as possible and the largest possible catchment area (i.e. as much of the roof area as possible) is connected to the RWH storage tank. If RWH were to be encouraged in SA, and the Liesbeek River Catchment in particular, it should be in line with Scenarios 8-10, ideally Scenario 10 . Naturally, subsidising RWH, e.g., by contributing to the capital expenses, would make a difference but that would be simply shifting the economic burden from the homeowner to local or national government (and indirectly back to the homeowner through increased rates and taxes).

\section{The impact of climate change}

The impact of climate change is increasingly a concern for water resource managers. An analysis of the impact of climate change on the viability of RWH was therefore undertaken using downscaled rainfall data based on the CMIP5 models (Coupled Model Inter-Comparison Project Phase 5). The data were based on two (RCP4.5 and RCP8.5) of the Representative Concentration Pathways (RCPs) as discussed in Van Vuuren et al. (2011). The results presented in this paper are, in the interests of brevity, based on the average system performance over the analysis period. However, as highlighted by, amongst others, Imteaz et al., (2011), there can be significant variations in performance of RWH between 'wet' and 'dry' years which may well be exacerbated by climate change.

Considering only Scenario 10, using tank sizes optimised using historical climate data and OF B, but now using various predicted climate change models (for the period 2050-2099), there is no clear trend; indeed the outputs are somewhat contradictory. While some climate change scenarios suggested increases of over $20 \%$ in volumetric reliability, others indicated a decrease of the same magnitude. The average change in volumetric reliability varied with a $4 \%$ increase for properties in Bishopscourt to a $4 \%$ decrease for properties simulated using the Observatory rainfall station. With respect to spillage (overflow) there was a general trend for an overall increase in spillage for properties in Bishopscourt (extreme values of 50\%) and a slight decrease in spillage for the Observatory station. This is expected due to the significant variations in evaporation and rainfall between these two stations already mentioned. This variation is then reflected in the economic analyses; since the cost of RWH is closely linked to volumetric reliability, a change in volumetric reliability will have cost implications that will vary from system to system in a non-linear manner.

\section{Effect of changes in the discount rate}

In order to assess the implications of economic variability on the viability of RWH, a sensitivity analysis was conducted on the various scenarios using discount rates of $3.1-4.5 \%$ based on an analysis of SA's inflation and 10-year bond yields between 1997 and 2012. The analysis indicated that an increase in the discount rate will increase the cost per kilolitre of harvested rainwater by approximately $4.5 \%$ between the two extreme values.

\section{Stormwater management benefits}

A commonly cited benefit in the literature, especially in stormwater management manuals (e.g. Woods-Ballard et al., 2007; Armitage et al., 2013), is that RWH assists in stormwater management through attenuating peak flows and reducing runoff volumes. The results of this study indicate that RWH has the potential to significantly reduce, by up to $44 \%$, the runoff volume emanating from roofs in the catchment - but note that this is only a small proportion of the total runoff in the catchment. Whilst this reduction in runoff volume is valuable from a conventional stormwater management perspective, it is the peak flow rate that is the most important consideration from a flooding and risk point of view. The maximum potential reduction in peak flows is associated with $100 \%$ adoption of RWH (i.e. every property is harvesting rainwater) for as many end uses as possible, as this ensures the maximum available storage for each storm event.

A calibrated USEPA SWMM model of the catchment - as detailed in Fisher-Jeffes (2015) - was coupled with the URSHM model assuming 100\% adoption of Scenario 10. Figure 7 compares the modelled flow with and without RWH in the catchment, and illustrates that, for storm events with a recurrence interval (RI) of less than 1 week, RWH could reduce 


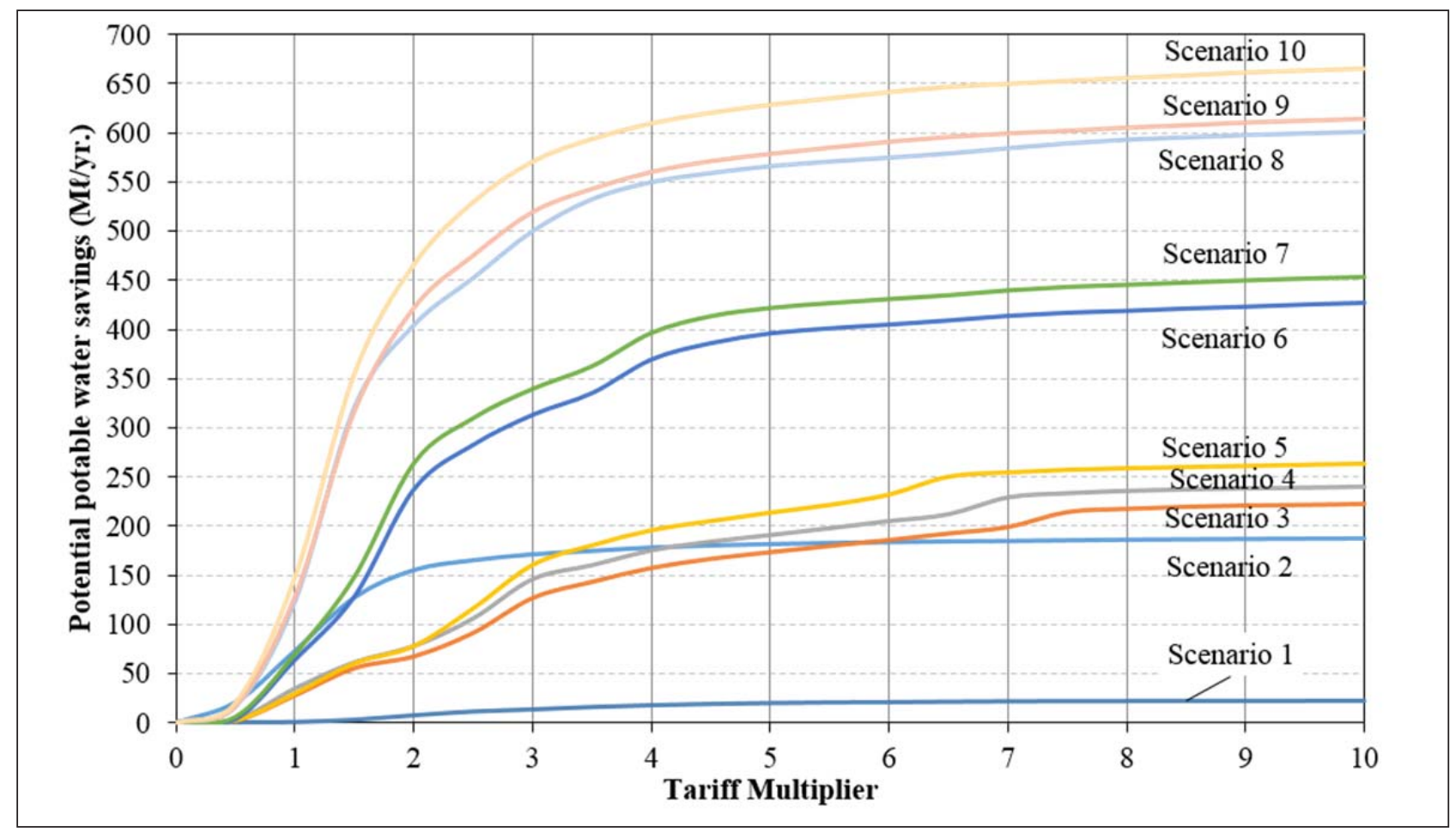

Figure 5

Maximum potable water savings (ML/yr) vs. cost of municipal water tariffs (Scenarios 1-10 using the full roof for collection)

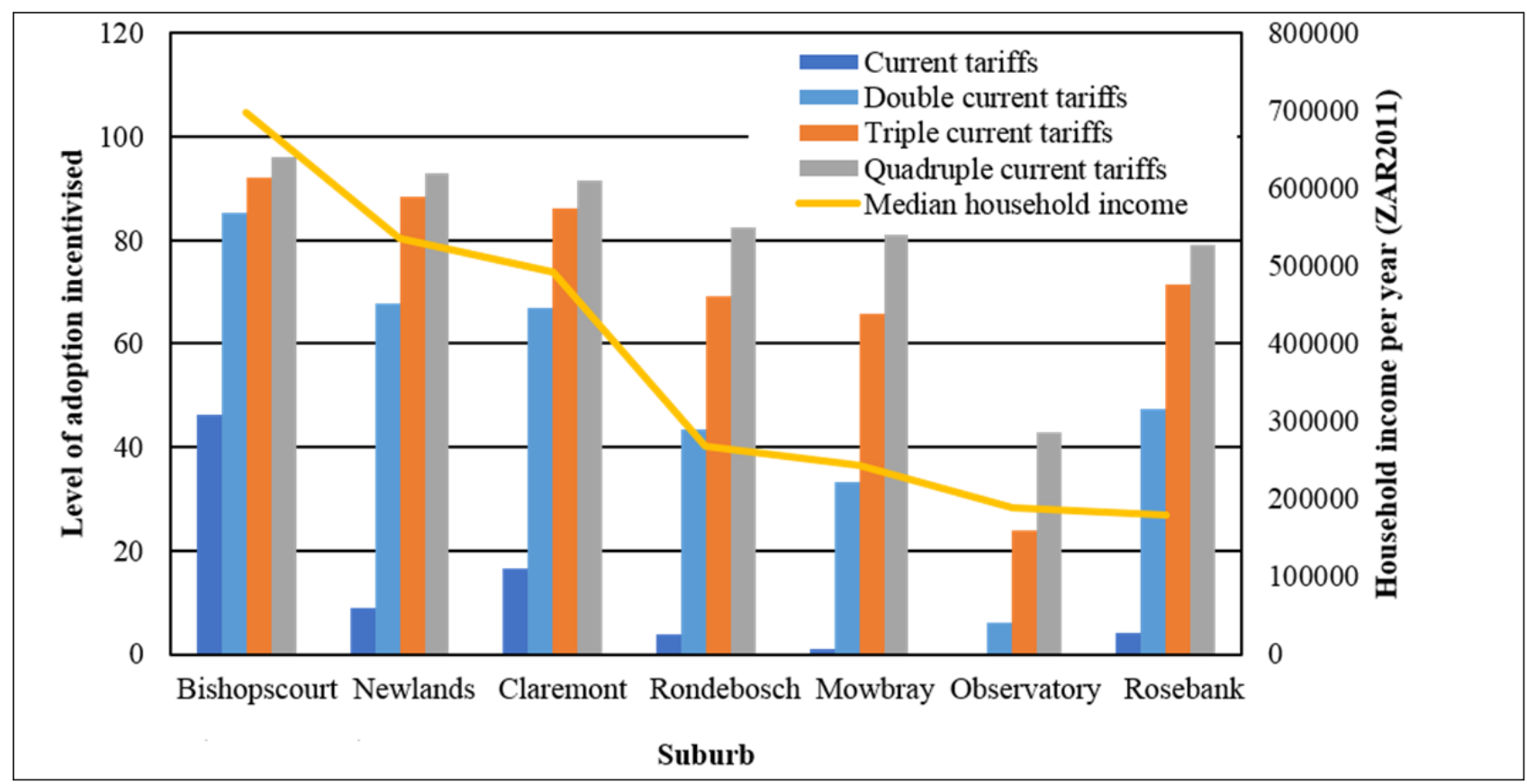

Figure 6

Suburb (as a proxy for wealth) vs. level of incentivised adoption

the peak flow by greater than $50 \%$ in more than $50 \%$ of events. However, the effectiveness of RWH quickly decreases as the RI increases. For events with a return period of 3 months, the reduction in peak flow in $17 \%$ of events is less than $2 \%$ and in $58 \%$ of events is less than $10 \%$. This is in line with results presented by Petrucci et al. (2012) and Campisano et al. (2014).
Figure 7 considers the catchment runoff and peak flows, which includes runoff from all surfaces. Further analysis indicates that, even if only considering the runoff from roofs in a catchment, RWH is an unreliable tool for stormwater management. This is significant, as the CoCT's 'Management of stormwater impacts policy' (CSRM, 2009) encourages the use of sustainable drainage systems (SuDS) - including RWH - to 
address a range of stormwater management objectives. The two relevant objectives of the policy are to: (i) detain the 1-year RI storm event on-site in order to reduce the downstream peak flows; and (ii) attenuate the peak flow of the 10-year RI storm event to predevelopment levels. While RWH could be used in conjunction with other SuDS, it is apparent that RWH is an unreliable means of achieving the first objective and is incapable of achieving the second. This applies at both the site and catchment scales.

Nevertheless, while RWH appears to offer negligible peak flow attenuation, it may well improve runoff water quality by intercepting pollutants prior to any spillage - captured by the coarse and/or first-flush filters or through sedimentation in the tanks. Dissolved pollutants will generally not, however, be removed.

\section{CONCLUSIONS}

RWH is generally not an economically viable option for the majority of residential households in the selected catchment (Liesbeek River, Cape Town) due to the cost of installing and maintaining RWH systems compared with the likely reduction in water bills. Currently it is only economically viable for a small minority of property owners - generally the most affluent - and then only under the following conditions:

- The largest possible catchment area (as much of the roof area as possible) is connected to the RWH storage tank.

- The harvested rainwater is used for as many end uses as possible.

If the local authority wishes to incentivise the widespread adoption of RWH by making it more economically attractive, it would need to either offer a subsidy to households who install RWH systems (e.g. to cover the capital costs) or to increase water tariffs by between 2 and 4 times over 2013 rates. This would be a significant increase that would likely meet considerable resistance from the population at large. By comparison, the 'Level 2' water restrictions that were in place at the time of analysis (2015), owing to the worst drought in decades, only resulted in a average $20 \%$ increase in the cost of water.

Climate change is typically a concern for water resource planners. The analysis demonstrated that, above all, the future is uncertain. While some climate change scenarios indicated significant decreases in runoff, others showed limited change. Overall, it seems reasonable to expect a slight decrease in volumetric reliability in the lower reaches (Observatory) of the catchment and a slight increase in volumetric reliability in the upper reaches (Bishopscourt). The change in cost per kilolitre is negatively correlated to volumetric reliability; it tends to decrease wherever volumetric reliability increases and vice versa.

RWH is sometimes considered an on-site stormwater management tool and is highlighted as such in some stormwater management guidelines. This study, however, suggests that it would not be particularly effective in this role in the Liesbeek River Catchment. While it does reduce the volume of runoff and may attenuate peak flows, it fails to significantly attenuate the peak flows of storms with longer RIs, i.e., the ones that do the damage. With this in mind, the only significant stormwater management benefits provided by RWH are the slight water quality improvement that may be realised through the interception of pollutants prior to any spillage. However, dissolved pollutants will not be removed.

There is scope for future research that could aid in better understanding the viability of rainwater harvesting, such as, inter alia: the viability of RWH in different climatic

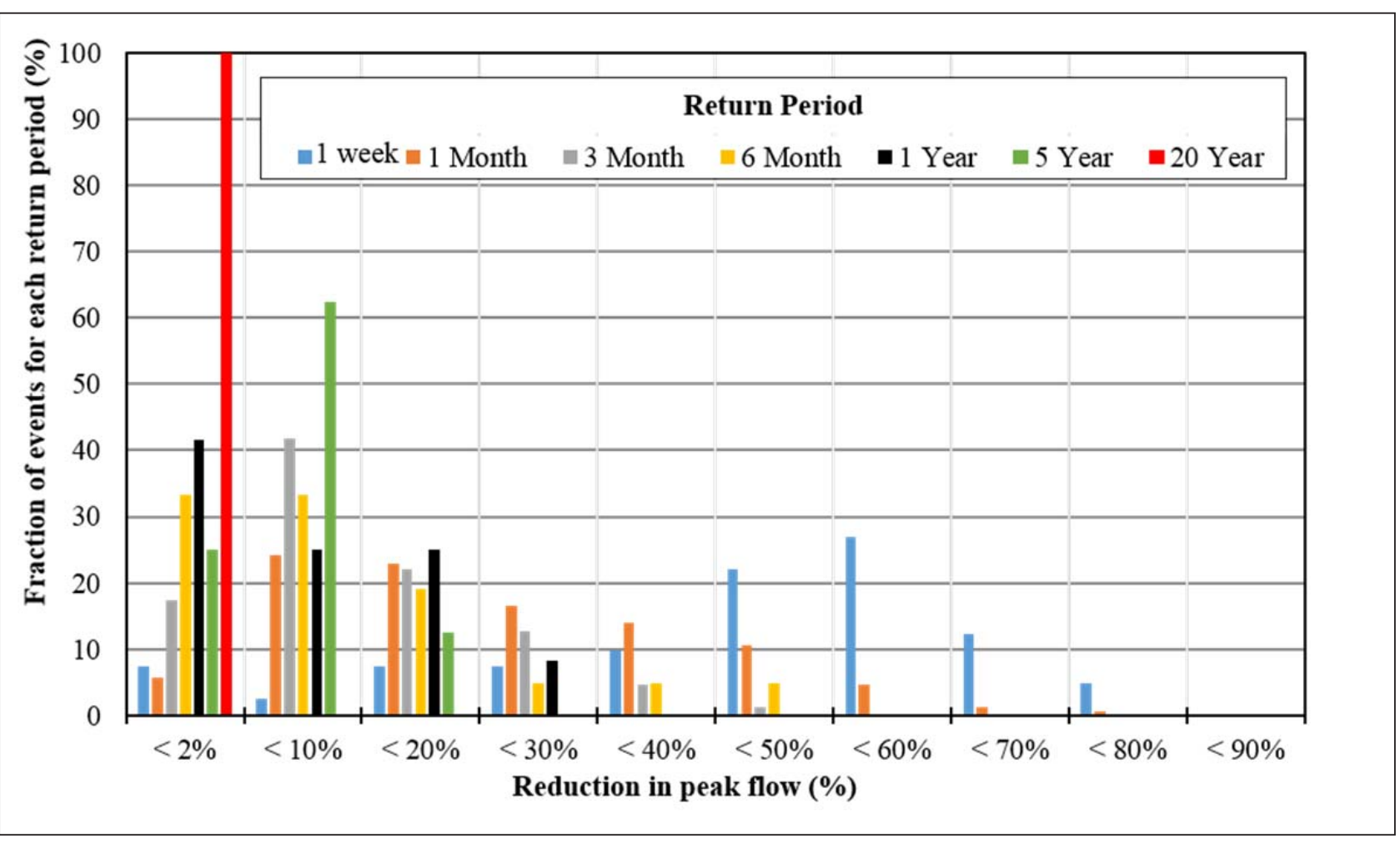

Figure 7

Distribution of the reduction of peak flow due to RWH in the Liesbeek River Catchment for different return periods, for all events between 2003-2012 
regions of South Africa; the social drivers for the uptake of rainwater harvesting; and the impact of rainwater harvesting on management.

\section{ACKNOWLEDGEMENTS}

Lloyd Fisher-Jeffes greatfully acknowledges the financial support of the Wilhelm Frank Trust which made this research possible.

\section{REFERENCES}

ARMITAGE N, VICE M, FISHER-JEFFES L, WINTER K, SPIEGEL A and DUNSTAN J (2013) South African Guidelines for sustainable drainage systems. WRC Report No. TT558/12. Water Research Commission, Pretoria.

BEAL C and STEWART R (2011) South East Queensland Residential End Use Study: Final Report. Urban Water Security Research Alliance Technical Report No . 47. http://www.urbanwateralliance. org.au/publications/UWSRA-tr47.pdf (Accessed 2 May 2014).

BLIGNAUT J and HEERDEN J (2009) The impact of water scarcity on economic development initiatives. Water SA 35 (4) 415-420.

BURNS M, FLETCHER T, DUNCAN H, HATT B and LADSON A (2012) The stormwater retention performance of rainwater tanks at the land- parcel scale. In: Proc. 7th International Conference on Water Sensitive Urban Design, 21-23 February 2012, Melbourne, Australia.

CAMPISANO A, DI LIBERTO D, MODICA C and REITANO S (2014) Potential for peak flow reduction by rainwater harvesting tanks. Procedia Engineering 89 1507-1514. https://doi.org/10.1016/j. proeng.2014.11.441

CARDEN K (2013) A measure of sustainability in the context of urban water management in South Africa. PhD thesis, University of Cape Town.

COCT (City of Cape Town) (2009) City of Cape Town GIS Database: Suburbs Shapefile. Shapefile, Strategic Information Department. City of Cape Town, South Africa.

COULTAS EH, MAHEEPALA S and MIRZA F (2011) Towards the quantification of water quantity and quality impacts of rainwater tanks in South East Queensland. In: $19^{\text {th }}$ International Congress on Modelling and Simulation, 12-16 December 2011, Perth. 12-16.

CSRM (Catchment, Stormwater and River Management) (2009) Management of urban stormwater impacts policy. City of Cape Town Catchment, Stormwater and River Management Branch, Transport, Roads, Stormwater and Major Projects Department. City of Cape Town, Cape Town.

DEA (Department of Environmental Affairs, South Africa) (2010) South African Country Report for the Eighteenth Session of the United Nations Commission on Sustainable Development (CSD-18). URL: http://www.un.org/esa/dsd/dsd_aofw_ni/ni_pdfs/NationalReports/ south_africa/SouthAfricanCSD18CountryReport.pdf (Accessed 3 April 2014).

DEBUSK K AND HUNT W (2014) Rainwater Harvesting: A Comprehensive Review of Literature. Report. No . 425. Water Resources Research Institute of The University of North Carolina, Farmville, Virginia.

DLGP (Department of Local Government and Planning, Queensland) (2008) Land Development Code, MP 4.2 Water Savings Targets. Department of Local Government and Planning. Queensland Government. URL: http://www.dsdip.qld.gov.au/resources/publication/ MP-4.2-water-savings-targets-current.pdf (Accessed 08 March 2015).

DWA (Department of Water Affairs, South Africa) (2013) National Water Resource Strategy 2: Water for an equitable and sustainable future. June 2013. Department of Water Affairs. Pretoria.

FISHER-JEFFES L (2015) The viability of rainwater and stormwater harvesting in the residential areas of the Liesbeek River Catchment, Cape Town. PhD thesis, University of Cape Town.

FISHER-JEFFES L, ARMITAGE N and CARDEN K (2014) Generating key WSUD modelling input data from municipal billing records. In: 13th International Conference on Urban Drainage, 7-11 September 2014. Kuching, Sarawak, Malaysia.

FISHER-JEFFES L, CARDEN K, ARMITAGE N, SPIEGEL A, WINTER K and ASHLEY R (2012) Challenges facing implementation of water sensitive urban design in South Africa. In: $7^{\text {th }}$ Conference on Water Sensitive Urban Design. Engineers Australia, Melbourne, Australia, Australia. ISBN: 9780858258952. 1-8

GHISI E, BRESSAN D and MARTINI M (2007) Rainwater tank capacity and potential for potable water savings by using rainwater in the residential sector of southeastern Brazil. Build. Environ. 42 (4) 1654-1666. https://doi.org/10.1016/j.buildenv.2006.02.007

HOWE CW and LINAWEAVER FP (1967) The impact of price on residential water demand and its relation to system design and price structure. Water Resour. Res. https://doi.org/10.1029/ WR003i001p00013

IMTEAZ MA, AHSAN A, NASER J and RAHMAN A (2011) Reliability analysis of rainwater tanks in Melbourne using daily water balance model. Resour. Conserv. Recy. 56 (1) 80-86. https://doi.org/10.1016/j. resconrec.2011.09.008

JACOBS H and HAARHOFF J (2004) Structure and data requirements of an end-use model for residential water demand and return flow. Water SA 30 (3) 293-304. https://doi.org/10.4314/wsa.v30i3.5077

JACOBS H, WRIGHT T, LOUBSER C and KOCK J (2011) Strategic assessment of household on-site water as supplementary resource to potable municipal supply - current trends and future needs. WRC Report No. 1819/1/10. Water Research Commission, Pretoria.

KOK P and COLLINSON M (2006) Migration and Urbanisation in South Africa. Report no. 03-04-02. Statistics South Africa, Pretoria URL: http://beta2.statssa.gov.za/publications/Report-03-04-02/ Report-03-04-02.pdf (Accessed 14 May 2014).

MAHEEPALA S, COULTAS E, NEUMANN L and SHARMA A (2013) Quantification of regional scale water quantity and quality implications of rainwater tanks in South East Queensland Urban Water Security Research Alliance Technical Report No. 104. Urban Water Security Research Alliance, Queensland, Australia. URL: http://www.urbanwateralliance.org.au/publications/ (Accessed 21 December 2014). ISBN: 1836-5566 (Online).

MAHEEPALA S, LOONAT N, MIRZA F and COULTAS E (2011) Quantifying potable water savings of rainwater tanks at a city scale by considering the effect of spatial lumping. In: Proc.OzWater 2011 Conference, 9--1 May 2011, Adelaide, Australia.

MARSDEN JACOBS ASSOCIATES (2006) Securing Australia's urban water supplies: opportunities and impediments - prepared for the Department of the Prime Minister and Cabinet. In: Philp M, Mcmahon J, Heyenga S, Marinoni O, Jenkins G, Maheepala S and Greenway M (2008). Review of Stormwater Harvesting Practices Urban Water Security Research Alliance Technical Report No. 9. Urban Water Security Research Alliance, Camberwell, Victoria, Australia.

MASHFORD J, MAHEEPALA S, NEUMANN L and COULTAS E (2011) Computation of the expected value and variance of the average annual yield for a stochastic simulation of rainwater tank clusters. In: International Conference on Modelling, Simulation and Visualisation Methods, 18-21 July 2011, Las Vegas. 303-309.

MAYER PW, DEOREO WB, OPITZ EM, KIEFER JC, DAVIS WY and DZIEGIELEWSKI B (1999) Residential end uses of water. American Water Works Association. URL: http://books.google.com/ books?hl=en\&lr=\&id=cHKl-eV-Q5MC\&pgis $=1$ (15 November 2014).

MITCHELL G and DIAPER C (2005) UVQ: a tool for assessing the water and contaminant balance impacts of urban development scenarios. Water Sci. Technol. 52 (12) 91-98.

MITCHELL G, SIRIWARDENE N, DUNCAN H and RAHILLY M (2008) Investigating the impact of temporal and spatial lumping on rainwater tank system modelling. In Lambert M, Daniell T and Leonard M (eds) Proc. Water Down Under 2008. Engineers Australia, Adelaide, Australia. ISBN: 0858257351. 54-65.

MWENGE KAHINDA J, TAIGBENU AE and BOROTO RJ (2010) Domestic rainwater harvesting as an adaptation measure to climate change in South Africa. Phys. Chem. Earth 35 (13-14) 742-751. https://doi.org/10.1016/j.pce.2010.07.004.

NEUMANN L, COULTAS E, MOGLIA M and MASHFORD J (2011) Errors in yield and overflow estimation in rainwater tank cluster modeling. In: $12^{\text {th }}$ International Conference on Urban Drainage, 10-15 September 2011, Porto Alegre, Brazil. 8.

PETRUCCI G, DEROUBAIX J-F, DE GOUVELLO B, DEUTSCH J-C, BOMPARD P and TASSIN B (2012) Rainwater harvesting to control stormwater runoff in suburban areas. An experimental 
case-study. Urban Water J. 9 (1) 45-55. https://doi.org/10.1080/1573 062X.2011.633610

ROEBUCK R (2007) A whole life costing approach for rainwater harvesting - an investigation into the whole life cost developments in the UK. PhD thesis, University of Bradford. https://doi.org/10.1080/1 573062X.2011.633610

ROBERTS P (2005) Yarra Valley Water 2004 Residential End Use Measurement Study. Yarra Valley Water, Melbourne, Australia. URL: http://www.manuelectronics.com.au/pdfs/ YarraValleyWater2004REUMS.pdf (Accessed 13 September 2013).

STATSOFT INC. (2013) Electronic Statistics Textbook. URL: http:// www.statsoft.com/textbook/. (Accessed November 2014).

UNDP, UNEP, WORLD BANK AND WORLD RESOURCES INSTITUTE (2000) A Guide to World Resources 2000 -2001. UNDP, UNEP, World Bank and World Resources Institute, Washington DC.

USEPA (United States Environmental Protection Agency) (2004) Storm Water Management Model (SWMM). United States Environmental Protection Agency. URL: http://www.epa.gov/athens/wwqtsc/html/ swmm.html (Accessed 23 June 2016).
VAN VUUREN DP, EDMONDS J, KAINUMA M, RIAHI K, THOMSON A, HIBBARD K, HURTT GC, KRAM T, KREY V, LAMARQUE JF, MASUI T, MEINSHAUSEN M, NAKICENOVIC N, SMITH SJ and ROSE SK (2011) The representative concentration pathways: An overview. Clim. Change 109 (1-2) 5-31. https://doi.org/10.1007/s10584-011-0148-z.

WILLIS R, STEWART RA, PANUWATWANICH K, CAPATI B and GIURCO D (2009) Gold coast domestic water end use study, (September). J. Aust. Water Assoc. 36 (6) 79-85.

WOODS-BALLARD B, KELLAGHER R, MARTIN P, JEFFERIES C, BRAY R, SHAFFER P and WALLINGFORD HR (2007) The SuDS Manual. CIRIA, London. ISBN: 9780860176978. URL: www.ciria.org. XU H, RAHILLY M and MAHEEPALA S (2010) Assessing the impact of spatial lumping on rainwater tank performance using daily modelling. In: Proc. $9^{\text {th }}$ International Conference on Hydroinformatics, 7-11 September 2010, Chinese Academy of Sciences, China. 